\title{
Influence of Incubation-Period Humidity on the Development of Brown Rot Blossom Blight of Sour Cherry
}

\author{
D. C. Koball, W. F. Wilcox, and R. C. Seem
}

Department of Plant Pathology, Cornell University, New York State Agricultural Experiment Station, Geneva 14456. Current address of D. C. Koball: Kohn Properties, P.O. Box 309, Calpella, CA 95418. Accepted for publication 1 October 1996.

\begin{abstract}
Koball, D. C., Wilcox, W. F., and Seem, R. C. 1997. Influence of incubation-period humidity on the development of brown rot blossom blight of sour cherry. Phytopathology 87:42-49.

When detached sour cherry (Prunus cerasus) blossoms were inoculated with conidia of Monilinia fructicola and subjected to a standard 8-h wetting treatment at $20^{\circ} \mathrm{C}$, blossom blight incidence was proportional to relative humidity $(\mathrm{RH})$ when $\mathrm{RH}$ was held constant during the subsequent 6-day incubation period (frequency $=1.0$ at the maximum $\mathrm{RH}$ of $92 \%$; frequency $=0.38$ at the minimum RH of $57 \%$ ). Similarly, when a primary incubation period at $87 \% \mathrm{RH}$ was followed by a secondary incubation period at $54 \% \mathrm{RH}$, blossom blight incidence was proportional to the number of hours at the higher level (frequencies of $0.94,0.80$, and 0.38 with primary incubation periods of 6 days, $36 \mathrm{~h}$, and $12 \mathrm{~h}$, respectively). When intact blossoms on potted trees were exposed to common

high on trees that subsequently were incubated in a controlled environment chamber $\left(20^{\circ} \mathrm{C}, 90\right.$ to $\left.95 \% \mathrm{RH}\right)$ but was extremely variable when trees were incubated under variable ambient conditions. Ambient incubation temperature had little effect on disease incidence 9 days after inoculation, whereas ambient $\mathrm{RH}$ had a pronounced effect: the frequency of blighted blossoms was 0.53 to 0.61 when the number of hours at $\mathrm{RH}$ $>90 \%$ was approximately two to six times that at $\mathrm{RH}<60 \%$, whereas this frequency was only 0.02 to 0.07 when the number of hours at RH $>90 \%$ was approximately one-third the number at $\mathrm{RH}<60 \%$. After $48 \mathrm{~h}$ at a constant $\mathrm{RH}$ of 89 or $57 \%$, the water potential of excised uninoculated blossoms was -1.15 and $-1.93 \mathrm{MPa}$, respectively; however, growth of $M$. fructicola on osmotically adjusted potato dextrose agar was unaffected by changes in water potential within this range. Thus, although RH during incubation has an important influence on blossom blight development, the causal mechanism remains uncertain.
\end{abstract} inoculation and wetting treatments, disease incidence was consistently
In eastern North America, the primary brown rot pathogen of stone fruits is Monilinia fructicola (Wint.) Honey, which causes blossom blight, twig blight, and fruit rot (27). Although fruit decay is recognized as the most consistently important phase of brown rot, blossom blight also can cause significant losses in certain years by reducing the number of flowers that set fruit and providing a source of inoculum for subsequent infection of the fruits that do form.

The effects of temperature and the dependence of the fungus on free moisture for germination of conidia are well established (2022 ), as are the optimal conditions for infection of fruits and flowers under controlled conditions $(1,6,7,20,22)$ and for sporulation from host tissues $(2,3)$. Nevertheless, it is curious that blossom blight occurs only sporadically in New York and other Great Lakes states, even though the pathogen is endemic, rain events during bloom are fairly common, and temperatures generally are sufficient for disease development (22). Thus, environmental factors other than free moisture and temperature may influence blossom blight development. For instance, Weaver (20) reported that the incidence of peach blossom blight caused by M. fructicola was strongly influenced by relative humidity $(\mathrm{RH})$ after a standard postinoculation wetting period, although his experiment was brief and examined only two postwetting RH regimes. Similarly, Wilcox (22) noted that variable RH conditions after controlled postinoculation wetting periods appeared to influence the subsequent incidence of blossom blight on sour cherry (Prunus cerasus L.) and suggested that environmental conditions during the incubation phase of the disease might influence its development under field conditions. However, no quantitative data were provided.

Corresponding author: W. F. Wilcox; E-mail address: wfw1 @ cornell.edu

Publication no. P-1996-1125-03R

(C) 1997 The American Phytopathological Society
Therefore, the primary objective of our work was to determine more precisely the extent to which blossom blight development is influenced by humidity during the incubation phase of the disease in both controlled and ambient environments. Furthermore, low atmospheric $\mathrm{RH}$ reportedly influences the activity of $M$. fructicola in infected tissues by altering their water content $(2,3)$; thus, a secondary objective of this study was to determine whether low humidity limits blossom blight development during the incubation phase of the disease by lowering the water potential of blossom tissues to a point that limits pathogen growth.

\section{MATERIALS AND METHODS}

Pathogen culture and inoculation procedures. A pure culture of $M$. fructicola was obtained by mass isolation from an overwintered sour cherry mummy onto potato dextrose agar (PDA) and subsequent transfer to canned peach halves. Inoculated fruit were incubated in a closed container at room temperature $\left(20\right.$ to $\left.23^{\circ} \mathrm{C}\right)$ for 7 days, stored at 2 to $3^{\circ} \mathrm{C}$, and the culture was retransferred to fresh peach halves every 1 to 2 months to maintain infectivity. For all experiments, blossoms were produced in a greenhouse on 4- to 16-year-old potted sour cherry trees (cv. Montmorency), inoculum was prepared by rinsing conidia from the peach-half cultures and adjusting their concentration with the aid of a hemacytometer, and the conidial suspensions were delivered to either intact or detached blossoms with a spray paint gun, as described previously $(22,23)$. Unless otherwise indicated, inoculated blossoms underwent a standard wetting period of $8 \mathrm{~h}$ at $20^{\circ} \mathrm{C}$ in laboratory mist chambers with constant fluorescent light prior to incubation under the various $\mathrm{RH}$ regimes.

Effect of incubation-period humidity on disease development. Flowers that had been open $24 \mathrm{~h}$ or less were excised from trees at the base of the pedicel, and all petals were removed from 
the blossoms in an effort to increase air flow around the stamens and stigma/style, thereby decreasing boundary layer effects directly adjacent to these tissues. The pedicel of each excised blossom was placed through a $2.5-\mathrm{mm}$ hole drilled into the attached cap of a 1.5-ml microcentrifuge tube (VWR Scientific, Rochester, $\mathrm{NY}$ ) that was filled with a $1.0 \%$ sucrose solution to supply carbohydrates to the blossom and maintain turgidity. Tubes containing single blossoms were placed arbitrarily in wire screen racks (35 tubes per rack), and blossoms were sprayed to runoff with a suspension containing 500 conidia of $M$. fructicola per ml. After an undisturbed 30-min period at ambient laboratory conditions to allow spores to settle, blossoms were moved to the mist chamber for the standard wetting period.

Upon completion of the wetting period, inoculated blossoms were held at ambient conditions in the laboratory until completely dry ( $90 \mathrm{~min})$. Then, 1 rack of 35 blossoms was placed into each of 10 sealed plastic treatment boxes $(15 \times 19 \times 25 \mathrm{~cm})$, which were components of two identical closed systems, each designed to provide five humidity levels simultaneously (Fig. 1). Both systems were entirely contained in a continuously lighted chamber maintained at $24^{\circ} \mathrm{C}$. For each system, an independent source of saturated air was provided by two pneumatic atomizers (model 73328 , Spraying Systems Co., Wheaton, IL) operating at a pressure of 204 $\mathrm{kPa}$ and was split five ways for the different treatments. Each humidity level was generated by bubbling the saturated air sequentially through two identical sealed tubs of a saturated salt solution and then to the treatment box. Outgoing air was exhausted through a vent hole located opposite the inlet hose. The five salts in saturated solution and the theoretical $\mathrm{RH}$ values associated with them at $25^{\circ} \mathrm{C}(26)$ were $\mathrm{KNO}_{3}(92.5 \%), \mathrm{KCl}(85.0 \%), \mathrm{NaCl}$ (75.5\%), $\mathrm{NaNO}_{2}(64.0 \%)$, and $\mathrm{Ca}\left(\mathrm{NO}_{3}\right)_{2}$ (56.5\%). $\mathrm{RH}$ was checked and recorded once daily during the experimental period with a wet-bulb psychrometer attached to the inlet line of each treatment chamber. The GLM analysis of variance (ANOVA) and Waller-Duncan mean separation test (SAS Institute, Cary, NC) were used to analyze the variability of the average daily $\mathrm{RH}$ determinations among the replicate points for each salt solution. Waller-Duncan groupings defined group means for RH levels among replications for each salt solution, and these means were used in the final statistical analysis of $\mathrm{RH}$ effects on blossom blight incidence (Table 1).

Treatments were maintained for 6 days after inoculation, and the number of blossoms blighted was recorded daily. Although a blossom was considered infected if a lesion was present on the floral cup (symptom stage 3 sensu Tamm et al. [17]), it was not considered blighted unless there was further development of the lesion into the pedicel (symptom stages 4 through 6 sensu Tamm et al. [17]). Two complete experiments were run two times each, because there were two independent sources of RH (saturated air and salt solution series) within the controlled temperature chamber during each run, providing a split-plot design, with the chamber as the main plot and the apparatus as the subplot. Initial ANOVA showed apparatus to be an insignificant variable with respect to blight incidence; thus, it was dropped from the final model, providing four replicate data points for each RH grouping. Data were blocked by replication, and blossom blight incidence was analyzed as a function of RH by the GLM and PROBIT procedures in SAS. The proportion of blossoms blighted was transformed for GLM by the equation

$$
P B l t=\left[\operatorname{arcsine}(b l t / n)^{1 / 2}\right] 57.295
$$

where blt is the number of blossoms blighted in the treatment, $n$ is the total number of blossoms in the treatment, 57.295 is a constant that converts radians to degrees (because the SAS arcsine function returns radians), and $P B l t$ is the transformed proportion of blossoms blighted, giving a model of the general form

$$
P B l t=\beta_{0}+\beta_{1}(R H)
$$

The PROBIT model in this case is of the form

$$
b l t / n=e^{\left(\beta_{0}+\beta_{1} R H\right) /\left[1+e^{\left(\beta_{0}+\beta_{1} R H\right)}\right]}
$$

where $n$ is the total number of blossoms in the treatment and $\beta_{0}$ and $\beta_{1}$ are parameters.

At the completion of the 6-day incubation period, 10 sporulating blossoms were selected at random from each treatment, placed in a glass test tube with $10 \mathrm{ml}$ of water and 2 drops of Triton X100 surfactant, and stored in a freezer until they could be assayed. The test tubes were removed to room temperature until completely thawed, vials were agitated for $15 \mathrm{~s}$ to remove conidia from the blossoms, and the concentration of conidia in the suspension was determined with a hemacytometer. Ten replicate hemacytometer readings were averaged and converted to represent the data as the number of conidia per blossom.

Effect of persistence of high humidity during incubation. Blossoms were excised and placed in vials, inoculated with a suspension containing 500 conidia of $M$. fructicola per $\mathrm{ml}$, and provided the standard 8-h wetting period, as described previously. After the wetting period, blossoms were dried at room temperature for $30 \mathrm{~min}$ with the aid of a fan, and 100 arbitrarily selected blossoms were placed in each of four treatment chambers maintained at $24^{\circ} \mathrm{C}$ and an average $\mathrm{RH}$ of $87 \%$, which was controlled and monitored as described before (daily range $=80$ to $90 \% \mathrm{RH}$ ). After 12 h, 50 blossoms were selected arbitrarily from a single chamber and transferred to a new chamber maintained at $24^{\circ} \mathrm{C}$ and an average $\mathrm{RH}$ of $54 \%$ (daily range $=48$ to $59 \%$ ). This pro-

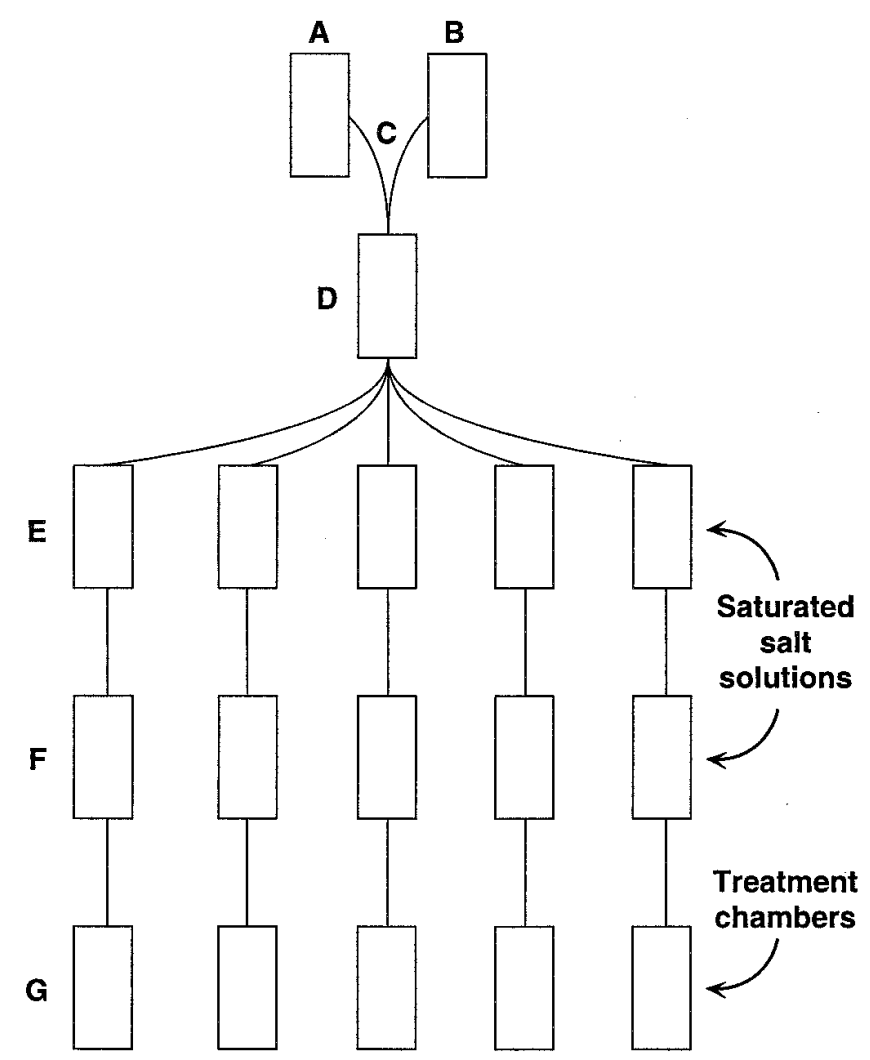

Fig. 1. System for conditioning air at a controlled relative humidity (RH) in which sour cherry blossoms inoculated with Monilinia fructicola were incubated at $24^{\circ} \mathrm{C}$. Units indicated by rectangles represent sealable plastic foodstorage containers $(15 \times 19 \times 25 \mathrm{~cm})$. A common source of saturated air was generated by two pneumatic atomizers spraying into A and B, passed through plastic tubing (C) to the condensation chamber (D), and split to provide five RH treatments. For each RH treatment, air was bubbled sequentially through two containers of identical saturated salt solution (E and F) and then progressed to the treatment chamber $(\mathrm{G})$ where blossoms were located. Two replicate closed systems were assembled within a continuously lighted controlled-temperature chamber and connected to independent sources of air and water for atomizers. 
cess was repeated at 18,24 , and $36 \mathrm{~h}$ after the wetting period, each time transferring 50 blossoms from an unsampled $87 \% \mathrm{RH}$ chamber to an empty 54\% RH chamber. The remaining 50 blossoms in each $87 \% \mathrm{RH}$ treatment chamber were maintained at that level as positive checks for infectivity. The numbers of blossoms infected and blighted were determined daily until 6 days after inoculation, and the experiment was repeated four times. After arcsine transformation of the proportion of blossoms blighted, data were analyzed by the GLM procedure to determine the significance of the time treatments.

Disease development under ambient versus controlled incubation environments. Potted sour cherry trees were induced to bloom, all unopened blossoms were removed, and the remaining intact blossoms (open $\leq 24 \mathrm{~h}$, mean number $=70$ to 100 blossoms per tree) were sprayed with conidia of $M$. fructicola. Thirty minutes after inoculation, trees were moved to a nearby screenhouse for wet-period treatments. The screenhouse provided shelter from rain but allowed exposure to ambient temperature and $\mathrm{RH}$.

A mist generator system similar to that used by Shaw et al. (15) was constructed with minor modifications for wet-period control and environmental monitoring. Mister nozzles (Monarch M-2, A. W. Westgate, Davis, CA) were attached vertically to metal fence posts $91 \mathrm{~cm}$ apart on opposite sides of each tree and adjusted to provide maximum coverage of inoculated blossoms. To consolidate the area requiring coverage, the branches were tied to group

TABLE 1. Theoretical and measured relative humidity (RH) of air used in experiments to examine the influence of humidity on the development of blossom blight of sour cherry during the incubation phase of disease development

\begin{tabular}{|c|c|c|c|c|c|}
\hline \multirow[b]{3}{*}{ Salt $^{t}$} & \multirow[b]{3}{*}{ Replicate } & \multicolumn{4}{|c|}{$\mathrm{RH}(\%)$} \\
\hline & & \multirow[b]{2}{*}{ Theoretical $^{u}$} & \multicolumn{3}{|c|}{ Measured } \\
\hline & & & Range $^{v}$ & Mean $^{w}$ & $\begin{array}{l}\text { Group } \\
\text { mean }^{\mathrm{x}}\end{array}$ \\
\hline \multirow[t]{4}{*}{$\mathrm{KNO}_{3}$} & 1 & 92.5 & $90-95$ & $92.2 \mathrm{a}$ & 91.7 \\
\hline & 2 & & $88-91$ & $90.4 \mathrm{a}, \mathrm{b}$ & \\
\hline & 3 & & $88-95$ & $92.2 \mathrm{a}$ & \\
\hline & 4 & & $89-95$ & $92.0 \mathrm{a}$ & \\
\hline \multirow[t]{4}{*}{$\mathrm{KCl}$} & 1 & 85.0 & $81-86$ & $84.6 \mathrm{c}$ & 85.1 \\
\hline & 2 & & $83-85$ & $84.0 \mathrm{c}$ & \\
\hline & 3 & & $82-95$ & $87.2 \mathrm{~b}, \mathrm{c}$ & \\
\hline & 4 & & $83-85$ & $84.4 \mathrm{c}$ & \\
\hline \multirow[t]{4}{*}{$\mathrm{NaCl}$} & 1 & 75.5 & $74-78$ & $75.8 \mathrm{~d}$ & $75.9^{y}$ \\
\hline & 2 & & $71-80$ & $75.4 \mathrm{~d}$ & \\
\hline & 3 & & $76-81$ & $78.0 \mathrm{~d}$ & \\
\hline & 4 & & $72-77$ & $75.4 \mathrm{~d}$ & \\
\hline \multirow[t]{4}{*}{$\mathrm{NaNO}_{2}$} & 1 & 64.0 & $64-71$ & $66.8 \mathrm{e}$ & 67.2 \\
\hline & 2 & & $65-69$ & $67.6 \mathrm{e}$ & \\
\hline & 3 & & $\ldots^{\mathrm{z}}$ & & $\ldots$ \\
\hline & 4 & & $64-69$ & $67.2 \mathrm{e}$ & \\
\hline \multirow[t]{4}{*}{$\mathrm{Ca}\left(\mathrm{NO}_{3}\right)_{2}$} & 1 & & $69-76$ & $74.8 \mathrm{~d}$ & $75.9^{y}$ \\
\hline & 2 & 56.5 & $52-65$ & $58.8 \mathrm{f}$ & 57.2 \\
\hline & 3 & & & & $\ldots$ \\
\hline & 4 & & $51-57$ & $55.6 \mathrm{f}$ & \\
\hline
\end{tabular}

${ }^{t}$ Water-saturated air was bubbled sequentially through two vessels containing saturated solutions of the indicated salt prior to delivery to the treatment chamber.

u Theoretical RH of treated air at $20^{\circ} \mathrm{C}$.

${ }^{v} \mathrm{RH}$ was measured daily using a wet-bulb psychrometer attached to the air inlet line of the treatment chamber.

${ }^{w}$ Mean of six daily measurements. Means not followed by a common letter are significantly different $(P=0.05)$ according to the Waller-Duncan exact Bayesian $k$ ratio LSD rule.

${ }^{x}$ Means over all blocks for the specified salt solution or Waller-Duncan grouping.

${ }^{y}$ Disease incidence and $\mathrm{RH}$ data from block 1 of the $\mathrm{Ca}\left(\mathrm{NO}_{3}\right)_{2}$ treatment were analyzed with data from the four $\mathrm{NaCl}$ treatment blocks due to statistical similarities in measured $\mathrm{RH}$ values.

${ }^{\mathrm{z}}$ Missing treatment resulting from technical problems. the inoculated blossoms in a central cluster within the spray cone. Blossoms were misted with tap water delivered at a pressure of $408 \mathrm{kPa}$ for approximately $4 \mathrm{~s}$ every $4 \mathrm{~min}$ throughout the duration of the wet period. After misting had begun, any blossoms that appeared dry were pinched off at the base.

Six trees were used for each of three wetting periods $(8,24$, and $48 \mathrm{~h}$ ): two were inoculated with 50,000 conidia per $\mathrm{ml}$, and four were inoculated with 5,000 conidia per ml. Upon completion of each wet period, two of the four trees inoculated with 5,000 conidia per $\mathrm{ml}$ were moved for the duration of the incubation period to a controlled environment chamber with constant light at $20^{\circ} \mathrm{C}$ and 90 to $95 \%$ RH. High humidity was maintained by keeping the floor of the chamber uniformly wet at all times, and RH levels were monitored with a sling psychrometer. At the same time, the remaining two trees receiving 5,000 conidia per $\mathrm{ml}$ and the two receiving 50,000 conidia per $\mathrm{ml}$ were moved to a section of the screenhouse $\sim 5 \mathrm{~m}$ away from the mist system for incubation under ambient conditions. A Campbell Scientific (Logan, UT) model CR10 datalogger, which was used to control the mist generator, also was used to monitor ambient temperature and RH. RH was monitored with the aid of aspirated wet- and dry-bulb temperature probes (Campbell Scientific model 107) and recorded on an hourly basis, whereas temperature was recorded every half-hour with the dry sensor. Both monitoring periods began with the start of controlled misting and continued for the duration of each run of the experiment. The numbers of blossoms infected and blighted were recorded daily for both incubation regimes beginning 3 days after inoculation and continuing for an additional 6 days. Data were expressed as the proportion of blossoms infected or blighted per tree at the end of the incubation period. The experiment was run five times between May and July, providing five sets (blocks) of ambient incubation conditions.

The data were analyzed with respect to incubation regime. Data from the trees incubated in the controlled environment chamber were analyzed as a complete block design, with wet period as the main effect, whereas data from the trees exposed to two inoculum levels and incubated under ambient conditions were analyzed as a

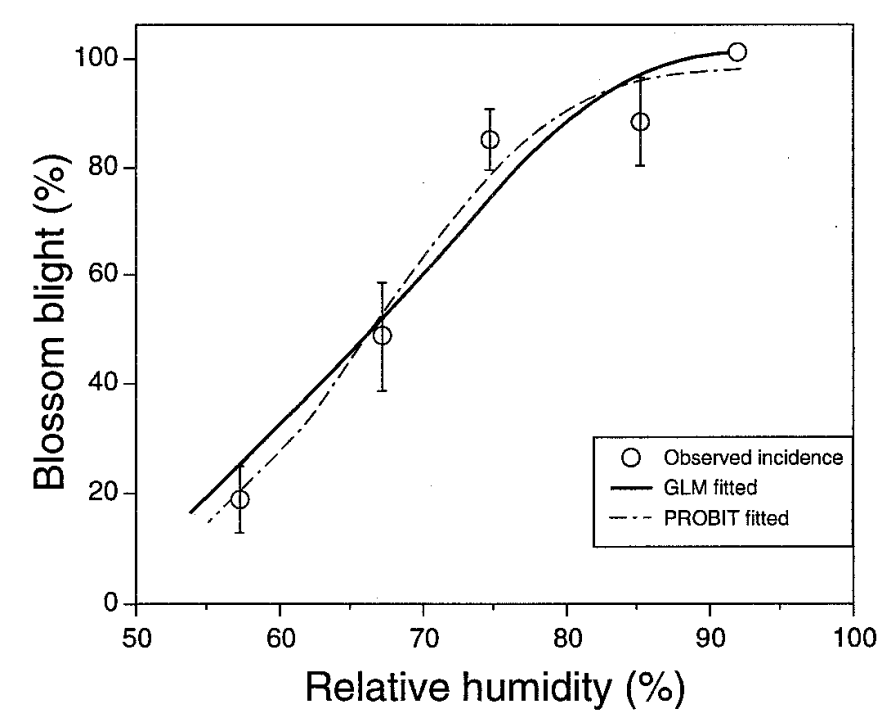

Fig. 2. Percentage of sour cherry blossoms blighted by Monilinia fructicola as a function of relative humidity $(\mathrm{RH})$ during incubation. Excised blossoms were inoculated with $M$. fructicola, subjected to an 8 -h wetting period at $20^{\circ} \mathrm{C}$, and allowed to dry under ambient laboratory conditions. Blossoms were subjected to constant $\mathrm{RH}$ treatments at $20^{\circ} \mathrm{C}$ for 6 days, after which disease incidences were recorded. Disease was defined on the basis of a lesion extending from the floral cup into the pedicel. Each data point represents the mean of four replicate measurements at mean $\mathrm{RH}$ values of 91.7, 85.1, and 67.2\%; five replicate measurements at a mean RH of $75.9 \%$; and two replicate measurements at a mean RH of $57.2 \%$. Vertical error bars represent two standard deviations of the means. 
split-plot design, with wet period as the main plot and inoculum level as the subplot. Furthermore, incubation regimes were contrasted at comparable inoculum levels and wetting treatments as a split-plot design, with block (run of the experiment) as the main plot and incubation regime as the subplot. Treatment significance levels were determined on the basis of the proportion of blossoms blighted, using ANOVA as described above; data were subjected to arcsine square-root transformation prior to analysis.

Effect of RH on blossom water potential. Uninoculated blossoms were excised at the base of the pedicel $\leq 24 \mathrm{~h}$ after opening and placed in $1.5-\mathrm{ml}$ microcentrifuge tubes filled with a $1 \%$ sucrose solution. Blossoms were exposed to one of three RH levels provided by saturated salt solutions in a treatment chamber maintained at $20^{\circ} \mathrm{C}$ with continuous light, as described above. The theoretical $\mathrm{RH}$ values of the respective salts at $25^{\circ} \mathrm{C}$ were $92.5 \%$ $\left(\mathrm{KNO}_{3}\right), 75.5 \%(\mathrm{NaCl})$, and $50.5 \%\left(\mathrm{Ca}\left(\mathrm{NO}_{3}\right)_{2}\right)$. Water potential of the blossom tissue was measured prior to treatment and after 24 and $48 \mathrm{~h}$ of exposure to the various $\mathrm{RH}$ levels, using a Decagon model SC-10 thermocouple psychrometer (Decagon Devices, Inc., Pullman, WA) with a ceramic bead thermocouple and dew point microvoltmeter (model HR-33, Wescor Electronics, Logan, UT). This instrument allowed measurement of water potential of up to 10 samples in quick succession. For this purpose, the stamens and stigma/style of the blossoms were removed while still exposed to the treatment $\mathrm{RH}$ by first placing the blossoms in a plastic bag into which flowed treated air and then excising these sample tissues at the level of the floral cup with a razor blade. The excised tissues from 10 blossoms were deposited into a sample cup, which was quickly placed into the psychrometer. A 3-h period was allowed for thermal and vapor equilibration in the sample chamber before water potential measurements were taken, after which the sample tissue was discarded. Two potassium chloride $(\mathrm{KCl})$ solutions with known water potentials similar to those of the samples were run simultaneously for calibration purposes. The water potential of two replicate groups of 10 blossoms at each RH level and time period was measured for each of seven runs of the experiment (except for pretreatment water potential measurements, which were conducted for the final four runs only); each experimental run was considered a block for statistical analysis. Data were subjected to ANOVA for a split-plot design, with block as the main plot and duration of RH treatment as the subplot.

Effect of water potential on growth of $\boldsymbol{M}$. fructicola. The water potential of PDA was determined psychrometrically with a Decagon SC-10 thermocouple psychrometer and HR-33 dew point microvoltmeter, using two 1-cm agar disks per sample cup and a 2-h thermal and vapor equilibration period. Water potentials were adjusted to values between -1.0 and $-6.1 \mathrm{MPa}$ by amending the medium with various quantities of $\mathrm{NaCl}, \mathrm{KCl}, \mathrm{CaCl}_{2}$, or sucrose. Water potentials of amended media were calculated as the sum of

Fig. 3. Influence of incubation climate on the incidence of diseased sour cherry blossoms after inoculation with Monilinia fructicola. Potted trees were induced to bloom, inoculated with either 5,000 or 50,000 conidia per $\mathrm{ml}$ of the pathogen, and misted constantly for either 8,24 , or $48 \mathrm{~h}$ in an outdoor screenhouse protected from rain. Immediately thereafter, trees were incubated for the remainder of the 9-day experimental period either (i) in a controlled environment chamber, maintained constantly at $20^{\circ} \mathrm{C}$ and 90 to $95 \%$ relative humidity (RH) (solid bars); or (ii) under ambient temperature and RH conditions in the outdoor screenhouse (hatched bars). For each of the five individual runs (blocks) of the experiment, data are presented for six inoculation regimes, designated by inoculum concentration $\left(10^{3}\right.$ conidia per $\left.\mathrm{ml}\right)$ followed parenthetically by the initial wetting-period duration (in hours). No trees were incubated in the controlled environment chamber after inoculation with 50,000 conidia per $\mathrm{ml}$ of the pathogen, as indicated by the asterisk corresponding to disease incidences for these treatments. Data in the top half of the graph for each block denote incidences of blossom infection (lesion confined to the floral cup); data in the bottom half denote incidences of blossom blight (lesion extending from the floral cup into the pedicel). the measured water potential of unamended PDA plus the theoretical water potential provided by the appropriate osmoticum at the same concentration in pure water $(10,13,16)$. The $\mathrm{pH}$ values of the amended media at the lowest and highest solute concentrations, respectively, were 5.5 for $\mathrm{KCl}$ (both concentrations), 5.5 and 5.2 for $\mathrm{NaCl}, 5.2$ and 4.5 for $\mathrm{CaCl}_{2}$, and 5.5 for sucrose (both concentrations); the $\mathrm{pH}$ of unamended PDA was 5.6.

M. fructicola was grown on unamended PDA for 1 week at $19^{\circ} \mathrm{C}$, after which 4-mm-diameter plugs were taken from the ad-

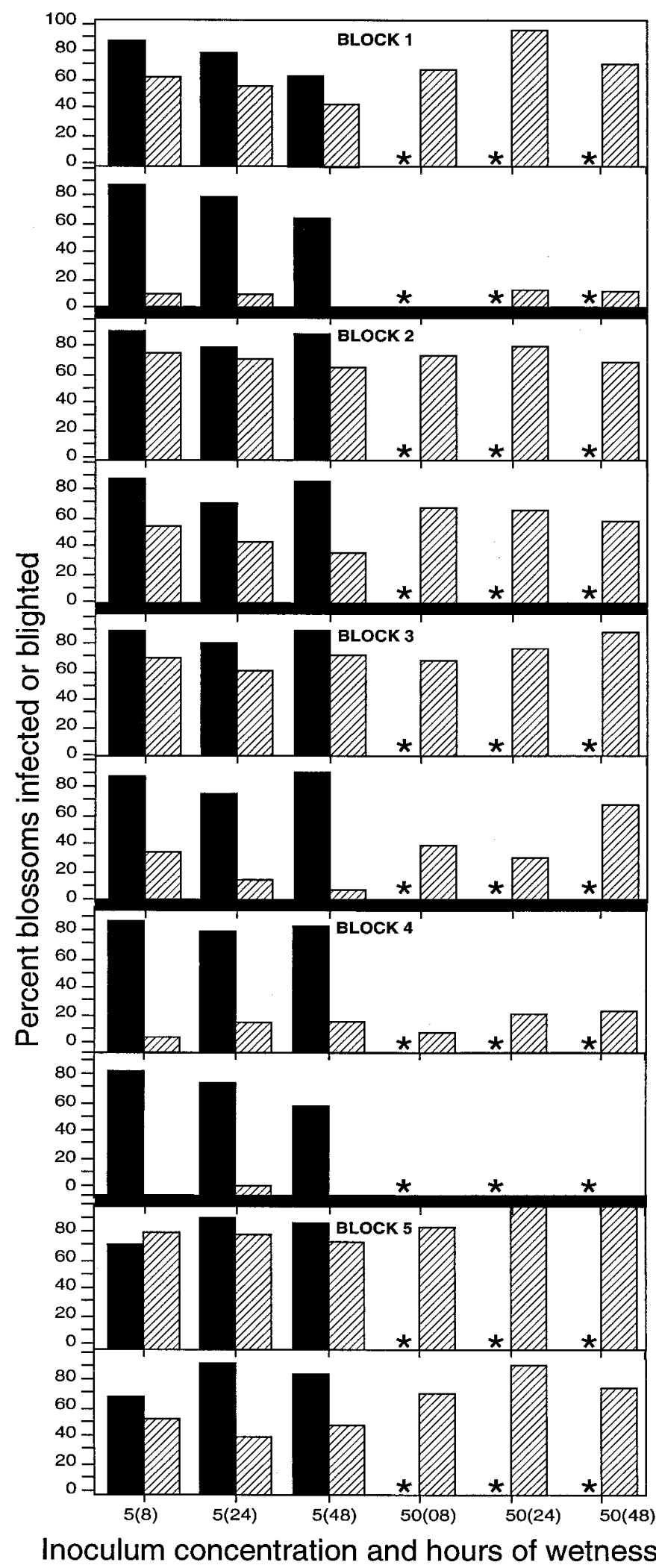


vancing colony margin and transferred to osmotically adjusted plates, with five replicate plates per treatment. Plates were wrapped in Parafilm, incubated upside down for 4 days at $20^{\circ} \mathrm{C}$, and the radial growth of the colonies was measured. The experiment was run twice, once in constant light and once in intermittent light (12 $\mathrm{h}$ light/12 h dark).

\section{RESULTS}

Effect of incubation-period humidity on disease development. When excised blossoms were subjected to a standard inoculation and wetting treatment, blight incidence was proportional to RH during the subsequent incubation period (Fig. 2). All blossoms were blighted at $92 \% \mathrm{RH}$, and disease incidence declined only moderately with incubation at mean $\mathrm{RH}$ values of 85 and $76 \%$. In contrast, disease incidence decreased dramatically at the two lowest humidities, with less than half of the blossoms blighted at a mean RH of $67 \%$, and less than one-fifth blighted at a mean $\mathrm{RH}$ of $57 \%$. The relationship between blossom blight incidence and RH was highly significant $(P=0.0001)$ and was described by the GLM model as

$$
P B l t=-70.425+1.743(R H)
$$

This model accounted for $87 \%$ of the variability in the data. A similar model was fit with the PROBIT procedure, and chi-square goodness-of-fit tests were highly significant $(P=0.0002)$. This model was

$$
b l t / n=e^{[-10.1289+0.1524(R H)]} /\left(1+e^{[-10.1289+0.1524(R H)]}\right)
$$

TABLE 2. Persistence of temperatures and relative humidity (RH) and associated disease incidences when potted sour cherry trees were incubated under five sets of ambient conditions (blocks) after inoculation of blossoms with Monilinia fructicola

\begin{tabular}{cccccc}
\hline & Block 1 & Block 2 & Block 3 & Block 4 & Block 5 \\
\hline $\begin{array}{c}\text { Cumulative hours } \\
\text { Temp. }\end{array}$ & & & & & \\
$0-5$ & & & & & \\
$5<x \leq 10$ & 48.5 & 6.0 & 11.5 & 8.5 & 0.0 \\
$10<x \leq 15$ & 51.0 & 68.5 & 51.0 & 43.5 & 12.5 \\
$15<x \leq 20$ & 33.5 & 75.0 & 64.5 & 58.0 & 104.0 \\
$20<x \leq 25$ & 25.5 & 48.0 & 55.0 & 64.5 & 71.5 \\
$25<x \leq 30$ & 26.0 & 18.5 & 28.5 & 36.0 & 26.0 \\
$x>30$ & 3.5 & 0.0 & 6.0 & 6.0 & 2.5 \\
RH $(\%)$ & & & & & \\
$x \leq 39$ & 39 & 10 & 32 & 29 & 0 \\
$40 \leq x \leq 50$ & 27 & 10 & 32 & 29 & 0 \\
$50<x \leq 60$ & 17 & 18 & 30 & 33 & 16 \\
$60<x \leq 70$ & 27 & 30 & 37 & 36 & 26 \\
$70<x \leq 80$ & 32 & 23 & 25 & 23 & 36 \\
$80<x \leq 90$ & 42 & 38 & 33 & 47 & 44 \\
$90<x \leq 100$ & 25 & 73 & 29 & 26 & 92 \\
Blossom infection & & & & & \\
incidence $(\%)^{\mathrm{z}}$ & $62.6 \mathrm{~b}$ & $71.6 \mathrm{~b}$ & $72.0 \mathrm{~b}$ & $17.8 \mathrm{c}$ & $85.3 \mathrm{a}$ \\
Blossom blight & & & & & \\
incidence $(\%)^{\mathrm{z}}$ & $6.7 \mathrm{c}$ & $52.9 \mathrm{a}$ & $30.6 \mathrm{~b}$ & $2.1 \mathrm{~d}$ & $61.0 \mathrm{a}$ \\
\hline
\end{tabular}

${ }^{y}$ Cumulative hours within the defined range over each 9-day experimental period. Ambient temperature was recorded every $30 \mathrm{~min}$ by a Campbell Scientific model CR10 datalogger; ambient RH was monitored hourly by aspirated wet- and dry-bulb temperature probes.

z Potted cv. Montmorency sour cherry trees were inoculated with either 5,000 or 50,000 conidia of $M$. fructicola per ml, subjected to an 8-, 24-, or 48-h wetting period, and incubated for the remainder of the 9-day experimental period in an outdoor screenhouse protected from rain. For each run of the experiment (block), reported disease incidences represent the mean values for 12 trees, i.e., three wetting periods $\times$ two inoculum concentrations $\times$ two trees per treatment. Blossoms were defined as infected if a necrotic lesion was present in the floral cup; they were defined as blighted if the lesion expanded into the pedicel. Means within a row not followed by a common letter are significantly different $(P=0.05)$ according to the Waller-Duncan exact Bayesian $k$ ratio LSD rule.
There was little difference between the fitted curves for the two models (Fig. 2).

Humidity level during the incubation period also influenced the rate of disease development. Blighted blossoms consistently were first observed 3 days after inoculation in the three highest RH treatments, and maximum or near-maximum incidences were reached by day 4 (mean $92 \% \mathrm{RH}$ ) or 5 (mean 76 and $85 \% \mathrm{RH}$ ). In contrast, blighted blossoms were seldom and never observed until day 4 in the 67 and $57 \%$ RH treatments, respectively, and disease incidences continued to increase through day 6 , at which time the experiment ended.

Lesions produced on blossoms incubated at $\mathrm{RH} \geq 85 \%$ were consistently water soaked, whereas the lesions on blossoms incubated at $\mathrm{RH} \leq 76 \%$ appeared quite dry. The number of conidia produced per blighted or infected blossom also decreased from an average of 37,000 in the $92 \% \mathrm{RH}$ treatment to only 500 to 2,000 in all treatments below this level.

Effect of persistence of high humidity during incubation. As the duration of high $\mathrm{RH}$ after an initial 8-h wetting period increased, the proportion of blossoms blighted also increased. For instance, when a 6.5-day incubation period was divided to provide a 12 -h primary incubation at $87 \%$ RH followed by a 6 -day secondary incubation at $54 \% \mathrm{RH}$, disease incidence was $37.5 \%$. However, blossom blight incidence increased to $43.5,47.0$, and $80.0 \%$ when the high-RH primary incubation period was increased to 18 , 24 , and $36 \mathrm{~h}$, respectively. By comparison, blossom blight incidence was $92.1 \%$ in the positive control, which received a continuous 6-day incubation at $87 \% \mathrm{RH}$. When ANOVA was performed on the transformed (arcsine square-root) of the proportion of blossoms blighted, the coefficient of determination was 0.89 , and main effects (block and time) were significant $(P=0.01)$, but their interaction was not.

Disease development under ambient versus controlled incubation environments. When intact blossoms on potted trees were exposed to common inoculation and wetting treatments, blossom blight incidence was consistently high on trees that were subsequently incubated in a controlled environment chamber $\left(20^{\circ} \mathrm{C}, 90\right.$ to $\left.95 \% \mathrm{RH}\right)$; in contrast, blight incidence varied greatly and often was much lower on companion trees that were incubated under the variable ambient conditions of the five runs (blocks) of the experiment. For instance, when averaged over all three initial wet-period durations $(8,24$, and $48 \mathrm{~h})$, blossom blight incidence ranged from 78 to $85 \%$ when trees were inoculated with 5,000 conidia per $\mathrm{ml}$ and incubated in the controlled

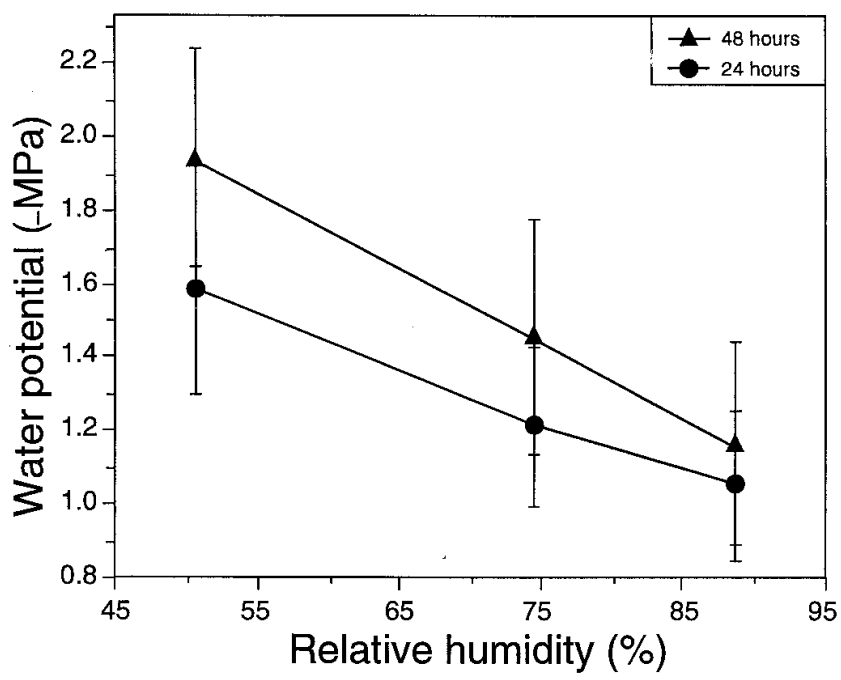

Fig. 4. Water potentials of excised, uninoculated sour cherry blossom stamens and stigma/styles after exposure to controlled relative humidities for 24 or $48 \mathrm{~h}$. Data points represent the means of seven replicate measurements per treatment, and vertical error bars are two standard deviations of the means. 
environment chamber but ranged from 2 to $61 \%$ on trees that were incubated concurrently under ambient conditions (Fig. 3). Because initial wet-period duration did not significantly affect disease incidence, data were analyzed as a complete block design with six replications (three wet periods $\times$ two trees) per inoculum level within each of the five blocks. ANOVA confirmed that incubation regime had a highly significant effect on blossom blight $(P=$ 0.001).

For trees incubated under ambient conditions, differences in blight incidence among blocks were correlated with differences in the persistence of extreme $\mathrm{RH}$ values during the experimental periods. For example, in the two runs (blocks 2 and 5) with the highest blight frequencies ( 0.53 and 0.61 , respectively), the corresponding proportions of the incubation period with $\mathrm{RH}>90 \%$ were 36 and $43 \%$, whereas the proportions of the incubation period with $\mathrm{RH} \leq 60 \%$ were 19 and $7 \%$, respectively. In contrast, in the two runs (blocks 4 and 1) with the lowest blight frequencies ( 0.02 and 0.07 , respectively), RH was $>90 \%$ for only $12 \%$ of the incubation period but was $\leq 60 \% 40$ to $41 \%$ of the time (Table 2). There was no consistent correlation between blight incidence and the range of temperatures encountered during the various experimental periods (Table 2).

For trees incubated under ambient conditions, the main effects of block and inoculum level were highly significant $(P=0.0001)$ for blossom blight incidence, and their interaction was significant $(P=0.02)$. This interaction is illustrated by the higher blight incidences on trees inoculated with 50,000 conidia per ml relative to those inoculated with 5,000 conidia per $\mathrm{ml}$ in blocks 2,3 , and 5 versus the uniformly low blight incidences produced by both inoculum levels in blocks 1 and 4 (Fig. 3).

Incidences of blossom infection (lesions confined to the floral cup) also were consistently higher and less variable among blocks for the controlled versus ambient incubation conditions. However, differences between the two incubation regimes were less pronounced than for blossom blight incidence (Fig. 3). ANOVA for blossom infection incidence on trees incubated under ambient conditions showed that the main effects of block and inoculum level were highly significant $(P=0.0001$ and 0.001 , respectively), but their interaction was not $(P=0.17)$.

Water potential of blossom tissue. The water potential of the stamen and stigma/style tissues of uninoculated blossoms decreased in response to decreasing $\mathrm{RH}$ and increased exposure time. Water potential of the blossom tissue after 24 and $48 \mathrm{~h}$ of exposure to the $89 \% \mathrm{RH}$ treatment was -1.03 and $-1.15 \mathrm{MPa}$, respectively, whereas it was -1.58 and $-1.93 \mathrm{MPa}$ for the $51 \% \mathrm{RH}$ treatment after the same respective periods (Fig. 4). Statistical analysis revealed that all main effects (block, time, and RH) and the interactions between block and time, were highly significant $(P=0.002$ to 0.0001$)$, with a coefficient of determination of 0.82 (Table 3). There was no distinct relationship between blossom water potential prior to treatment and final water potential after the described treatments when compared between blocks.

TABLE 3. Analysis of variance for blossom tissue water potential as a function of block, time, and humidity when excised, uninoculated sour cherry blossoms were maintained for 24 and $48 \mathrm{~h}$ at mean relative humidities $(\mathrm{RH})$ of 51 to $89 \%$

\begin{tabular}{lrrrrr}
\hline $\begin{array}{l}\text { Source of } \\
\text { variation }\end{array}$ & df & \multicolumn{1}{c}{ SS } & MS & $F$ value & $P>F$ \\
\hline Model & 16 & $1,008.3$ & 63.0 & 17.37 & 0.0001 \\
$\quad$ Block & 6 & 216.7 & 36.1 & 9.95 & 0.0001 \\
Time & 1 & 111.6 & 111.6 & 30.75 & 0.0001 \\
Block $\times$ time & 5 & 79.6 & 15.9 & 4.39 & 0.002 \\
RH & 2 & 583.2 & 291.9 & 80.44 & 0.0001 \\
RH $\times$ time & 2 & 16.6 & 8.3 & 2.29 & 0.11 \\
Error & 60 & 217.7 & 3.6 & & \\
Total & 76 & $1,226.0$ & & & $r^{2}=0.82$ \\
\hline
\end{tabular}

M. fructicola growth on osmotically adjusted media. Radial growth of the fungus decreased as water potential of the osmotically adjusted PDA decreased to values $\leq-2.6 \mathrm{MPa}$ (Fig. 5). However, growth was 10 to $35 \%$ greater on media adjusted to water potentials between -1.0 and $-2.0 \mathrm{MPa}$ than it was on unamended medium (water potential $=-0.72 \mathrm{MPa}$ ). At equivalent water potentials, growth of $M$. fructicola was greatest when sucrose was used as the osmoticum and least when $\mathrm{NaCl}$ and $\mathrm{CaCl}_{2}$ were used; for the latter two salts, radial growth was reduced by $\sim 40 \%$ (relative to unamended medium) at water potentials of -2.6 and -2.8 $\mathrm{MPa}$, respectively. Growth was consistently less on media incubated under intermittent rather than constant light, with the exception of sucrose-amended media, which did not appear to be affected by light regime (data not shown).

\section{DISCUSSION}

By exposing blossoms to a standard inoculation and wetting regimen and manipulating $\mathrm{RH}$ during the subsequent incubation period, we demonstrated the important influence of incubationperiod humidity on blossom blight development after a putative infection period. In experiments with detached blossoms, blight incidence was directly proportional to $\mathrm{RH}$ during the incubation period, with maximal levels developing at constant incubation $\mathrm{RH}$ levels $>90 \%$ and relatively low incidences developing at RH levels $<60 \%$. Furthermore, when RH during incubation was cycled between similar extremes, blight incidence was proportional to the number of hours at values near $90 \%$. These results were supported by related experiments with intact blossoms on potted trees exposed to common inoculation and wetting treatments and incubated under controlled versus ambient environments: (i) higher blossom blight incidences always developed on trees incubated under the controlled RH level of 90 to $95 \%$ than on trees incubated under ambient conditions with lower humidities, and (ii) under ambient conditions, the highest blossom blight incidences occurred when the ratio of hours at $\mathrm{RH}>90 \%$ versus $\mathrm{RH}<60 \%$ was 1.9 to 6.1 , whereas the lowest incidences occurred when this ratio was 0.3 . Weaver (20) observed a qualitatively similar relationship between the incidence of peach blossom blight and humidity after an initial postinoculation 8-h wetting period, obtaining 20 and $100 \%$ incidences at constant incubation RH levels of 80 and $90 \%$, respectively. Although we found that disease incidence decreased

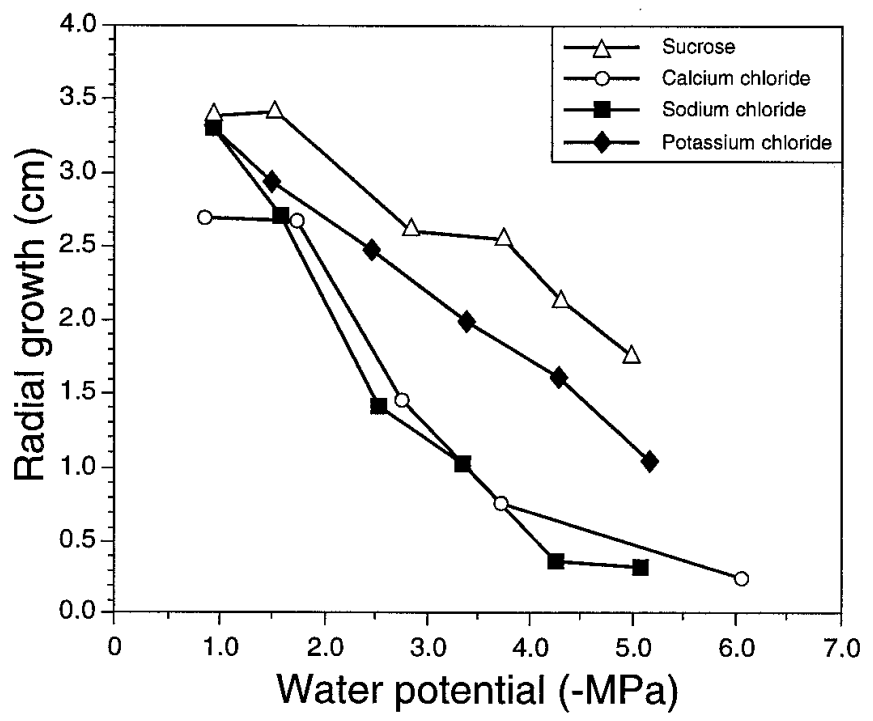

Fig. 5. Radial growth of Monilinia fructicola after 4 days at $20^{\circ} \mathrm{C}$ under a 12 $\mathrm{h}$ light/12 $\mathrm{h}$ dark regime on osmotically amended potato dextrose agar (PDA) at various water potentials. Each data point represents the mean of five replicates per treatment. The water potential of unamended PDA was $-0.72 \mathrm{MPa}$, and mean radial growth was $2.5 \mathrm{~cm}$. 
less abruptly as RH decreased below $90 \%$, both studies suggest that significant blossom blight is unlikely to develop when humidity remains below some critical threshold during the incubation period.

In contrast to the subsequent incubation regime, blossom blight incidence on potted trees was not significantly affected by the duration of the initial wet-period treatment within the tested range of 8 to $48 \mathrm{~h}$. Although Wilcox (22) demonstrated a direct effect of postinoculation wetness duration on the incidence of blossom blight (a definition that incorporated some instances of mere blossom "infection" as defined in the current paper), he also showed this effect to be more pronounced when sour cherry blossoms were inoculated with 50 or 500 conidia per ml rather than 5,000 conidia per $\mathrm{ml}$; at the latter concentration, blight incidence reached nearly maximal levels within only a few hours at temperatures $\geq 16^{\circ} \mathrm{C}$. Thus, with the inoculum concentrations of 5,000 and 50,000 conidia per ml used in the current study, maximum frequencies of conidium germination (22) and penetration may have occurred within the first $8 \mathrm{~h}$ of wetting, making further wetting superfluous for this initial stage of disease development. Tamm et al. (17) also showed that the majority of sweet cherry blossom infections caused by $M$. laxa occurred within the first $8 \mathrm{~h}$ of wetting at an inoculum concentration of 5,000 conidia per $\mathrm{ml}$ and temperatures $\geq 10^{\circ} \mathrm{C}$.

We consistently first observed blight of excised blossoms 1 day later when they were incubated at $57 \% \mathrm{RH}$ than at higher humidities; similarly, for intact blossoms on trees incubated under ambient conditions, the first blight was observed 2 to 3 days later in the experimental run least conducive to disease development (block 4) than in the other runs (data not shown). Comparable effects of low $\mathrm{RH}$ on the rate of disease development were observed by Weaver (20). Thus, we postulated that as $M$. fructicola grows intercellularly and is associated with phloem tissue in blossom stamens and stigma/styles (24), low atmospheric RH might limit growth of the fungal hyphae (and, thus, the rate and magnitude of disease development) by reducing the water potential of these organs. However, whereas water potential of the stamens and stigma/styles decreased with decreasing RH in our tests, growth by $M$. fructicola on osmotically adjusted PDA was substantially reduced only at water potentials below those measured in blossom tissue, similar to the responses reported for other fungi $(4,14,16)$. In fact, the relatively low concentrations of osmotica needed to provide water potentials mimicking those in blossom tissue increased fungal growth relative to that of nonadjusted medium. Thus, it is possible that these amendments provided a nutritional benefit to the fungus (16) that masked any negative effect of lower water potentials within this range. Therefore, although we were unable to explain how low humidity limits blossom blight development, we did demonstrate a relationship between diseaselimiting RH levels and lowered blossom water potential. Furthermore, we demonstrated that sporulation from infected blossom tissue also decreased sharply as $\mathrm{RH}$ decreased from $90 \%$ to disease-limiting levels, probably due to a reduced water content in blossom tissues in the lower RH treatments $(2,3,18)$. $\mathrm{RH}$ is recognized as an important influence on infection and sporulation $(2,3,5,11,12,18,25)$ in other host-pathogen systems as well.

Our results suggest that incubation-period humidity is an important environmental variable that warrants increased attention in future epidemiological studies of brown rot blossom blight. These results also suggest that blossom blight control programs should be influenced not only by inoculum availability, temperature, and wet-period durations during bloom (22), but also by humidity levels subsequent to such wet periods. The availability of fungicides with good curative activity against the disease (23) may ultimately facilitate a strategy of responding to a set of specific environmental conditions after they occur rather than prophylactically. However, it should be recognized that in our study, RH during incubation had less influence on the incidence of blossom infections confined to the floral cup than on the expansion of such lesions into the pedicel. Therefore, blossoms that become infected but do not blight may set fruit with the capacity for developing latent or quiescent infections $(8,9,19)$ if the calyces do not abscise (17) beforehand. It appears as if our data and previous studies on blossom blight biology $(17,20,22)$ are more applicable to understanding the principles governing disease development than they are to identifying the precise conditions for optimum prediction and control under field conditions. Nevertheless, these data should be useful for designing predictive models suitable for field validation.

\section{LITERATURE CITED}

1. Biggs, A. R., and Northover, J. 1988. Influence of temperature and wetness duration on infection of peach and sweet cherry fruits by Monilinia fructicola. Phytopathology 78:1352-1356.

2. Corbin, J. B. 1962. Factors determining the length of the incubation period of Monilinia fructicola (Wint.) Honey in fruits of Prunus spp. Aust. J. Agric. Res. 14:51-60.

3. Corbin, J. B., and Cruickshank, I. A. M. 1963. Environment and sporulation in phytopathogenic fungi. V. Monilinia fructicola (Wint.) Honey: Effect of water relations on regeneration of conidia in vivo. Aust. J. Biol. Sci. 16:99-110.

4. Dillard, H. R. 1988. Influence of temperature, $\mathrm{pH}$, osmotic potential, and fungicide sensitivity on germination of conidia and growth from sclerotia of Colletotrichum coccodes in vitro. Phytopathology 78:13571361.

5. Everts, K. L., and Lacy, M. L. 1990. The influence of dew duration, relative humidity, and leaf senescence on conidial formation and infection of onion by Alternaria porri. Phytopathology 80:1203-1207.

6. Good, H. M., and Zathureczky, P. G. M. 1967. Effects of drying on the viability of germinated spores of Botrytis cinerea, Cercospora musae, and Monilinia fructicola. Phytopathology 37:719-722.

7. Grindle, M., and Good, H. M. 1961. Effects of drying on the viability of germinated and germinating conidia of Monilinia fructicola (Wint.) Honey. Trans. Br. Mycol. Soc. 44:549-558.

8. Hockey, J. H. 1958. Calyx end rot of apples. Plant Dis. Rep. 43:804-805.

9. Jenkins, P. T., and Reinganum, C. 1965. The occurrence of a quiescent infection of stone fruits caused by Sclerotinia fructicola (Wint.) Rehm. Aust. J. Agric. Res. 16:131-140.

10. Milburn, J. A. 1979. Water Flow in Plants. Longman, Inc., New York.

11. Nelson, K. E. 1951. Effect of humidity on infection of table grapes by Botrytis cinerea. Phytopathology 41:859-864.

12. Rider, N. E., Cruickshank, I. A. M., and Bradley, E. F. 1961. Environment and sporulation in phytopathogenic fungi. III. Peronospora tabacina Adam: Field environment, sporulation, and forecasting. Aust. J. Agric. Res. 12:1119-1125.

13. Robinson, R. A., and Stokes, R. H. 1955. Electrolyte Solutions. Academic Press, New York.

14. Scott, W. J. 1957. Water relations of food spoilage microorganisms. Adv. Food Res. 7:83-127.

15. Shaw, D. A., Adaskaveg, J. E., and Ogawa, J. M. 1990. Influence of wetness period and temperature on infection and development of shot-hole disease of almond caused by Wilsonomyces carpophilus. Phytopathology 80:749-756.

16. Sommers, L. E., Harris, R. F., Dalton, F. N., and Gardner, W. R. 1970. Water potential relations of three root infecting Phytophthora species. Phytopathology 60:932-934.

17. Tamm, L., Minder, C. E., and Flückiger, W. 1995. Phenological analysis of brown rot blossom blight of sweet cherry caused by Monilinia laxa. Phytopathology 85:401-408.

18. Thomas, C. S., Marois, J. J., and English, J. T. 1988. The effects of wind speed, temperature, and relative humidity on development of aerial mycelium and conidia of Botrytis cinerea on grape. Phytopathology 78:260265 .

19. Wade, G. C. 1956. Investigations on brown rot of apricots caused by Sclerotinia fructicola (Wint.) Rehm. I. The occurrence of latent infection in fruit. Aust. J. Agric. Res. 7:504-515.

20. Weaver, L. O. 1950. Occurrence of blossom blight of stone fruits. Phytopathology 40:1136-1153.

21. Wellman, R. H., and McCallan, S. E. A. 1942. An analysis of factors causing variation in spore germination tests of fungicides. IV. Time and temperature. Contrib. Boyce Thompson Inst. Plant Res. 12:431-449.

22. Wilcox, W. F. 1989. Influence of environment and inoculum density on the incidence of brown rot blossom blight of sour cherry. Phytopathol- 
ogy 79:530-534.

23. Wilcox, W. F. 1990. Postinfection and antisporulant activities of selected fungicides in control of blossom blight of sour cherry caused by Monilinia fructicola. Plant Dis. 74:808-811.

24. Willer, K.-H. 1970. Anfärbung von parasitischen Pilzen im Gewebe höherer Pflanzen. Z. Wiss. Mikrosk. 70:49-57.
25. Wilson, A. R. 1936. The chocolate spot disease of beans (Vicia faba L.) caused by Botrytis cinerea Pers. Ann. Appl. Biol. 24:259-289.

26. Winston, P. W., and Bates, D. H. 1960. Saturated solutions for the control of humidity in biological research. Ecology 41:232-237.

27. Zehr, E. I. 1982. Control of brown rot in peach orchards. Plant. Dis. 66: 1101-1105. 